\title{
Thermodynamic and kinetic characteristics of a Cu-Mn composite oxygen carrier for low-temperature chemical- looping air separation
}

\author{
Citation for published version (APA): \\ Wang, K., Yu, Q., Wu, T., van Sint Annaland, M., \& Qin, Q. (2020). Thermodynamic and kinetic characteristics of \\ a Cu-Mn composite oxygen carrier for low-temperature chemical-looping air separation. Chemical Engineering \\ Journal, 393, [124792]. https://doi.org/10.1016/j.cej.2020.124792
}

\section{Document license: \\ TAVERNE}

DOI:

10.1016/j.cej.2020.124792

Document status and date:

Published: 01/08/2020

\section{Document Version:}

Publisher's PDF, also known as Version of Record (includes final page, issue and volume numbers)

\section{Please check the document version of this publication:}

- A submitted manuscript is the version of the article upon submission and before peer-review. There can be important differences between the submitted version and the official published version of record. People interested in the research are advised to contact the author for the final version of the publication, or visit the $\mathrm{DOI}$ to the publisher's website.

- The final author version and the galley proof are versions of the publication after peer review.

- The final published version features the final layout of the paper including the volume, issue and page numbers.

Link to publication

\footnotetext{
General rights

- You may freely distribute the URL identifying the publication in the public portal. follow below link for the End User Agreement:

www.tue.nl/taverne

\section{Take down policy}

If you believe that this document breaches copyright please contact us at:

openaccess@tue.nl

providing details and we will investigate your claim.
}

Copyright and moral rights for the publications made accessible in the public portal are retained by the authors and/or other copyright owners and it is a condition of accessing publications that users recognise and abide by the legal requirements associated with these rights.

- Users may download and print one copy of any publication from the public portal for the purpose of private study or research.

- You may not further distribute the material or use it for any profit-making activity or commercial gain

If the publication is distributed under the terms of Article $25 \mathrm{fa}$ of the Dutch Copyright Act, indicated by the "Taverne" license above, please 


\title{
Thermodynamic and kinetic characteristics of a Cu-Mn composite oxygen carrier for low-temperature chemical-looping air separation
}

\author{
Kun Wang ${ }^{\mathrm{a}, \mathrm{b}, *}$, Qingbo $\mathrm{Yu}^{\mathrm{a}}$, Tianwei Wu ${ }^{\mathrm{a}} \mathrm{b}$, Martin van Sint Annaland ${ }^{\mathrm{b}}$, Qin Qin $^{\mathrm{a}}$ \\ ${ }^{a}$ School of Metallurgy, State Environmental Protection Key Laboratory of Eco-Industry, Northeastern University, Shenyang 110819, China \\ ${ }^{\mathrm{b}}$ Chemical Process Intensification, Department of Chemical Engineering and Chemistry, Eindhoven University of Technology, Eindhoven 5600 MB, Netherlands
}

\section{H I G H L I G H T S}

- The Cu-Mn composite oxygen carrier with relatively low reaction temperature is constructed.

- The reactivity and oxygen transport capacity of this oxygen carrier are determined.

- The thermodynamic data including $\Delta G$ and $K_{\mathrm{p}}$ of the redox reaction are obtained.

- The redox kinetic models of the Cu-Mn composite oxygen carrier were established.

\section{A R T I C L E I N F O}

\section{Keywords:}

Chemical-looping air separation

Cu-Mn composite

Oxygen carrier

Thermodynamics

Kinetics

\section{G R A P H I C A L A B S T R A C T}

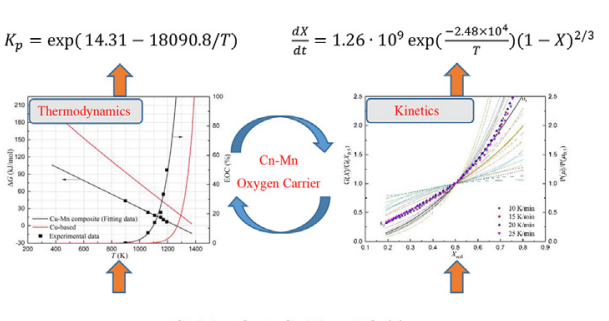

$\mathrm{Cu}_{x} \mathrm{Mn}_{3-x} \mathrm{O}_{4} \leftrightharpoons \mathrm{Cu}_{x} \mathrm{Mn}_{2-x}+\mathrm{O}_{2}(\mathrm{~g})$

\begin{abstract}
A B S T R A C T
The further development of the chemical-looping air separation (CLAS) technology is hindered by the required high redox temperature. Improving the thermodynamic properties of oxides by elemental composition is an effective way to decrease the reduction temperature of oxygen carrier. In this paper, a Cu-Mn composite oxygen carrier was prepared by the addition of $\mathrm{Mn}_{2} \mathrm{O}_{3}$ to $\mathrm{CuO}$, with $\mathrm{Cu}_{x} \mathrm{Mn}_{3-x} \mathrm{O}_{4}$ as the active phase, and the oxygen uncoupling properties of the $\mathrm{Cu}-\mathrm{Mn} / \mathrm{Zr}$ composite oxygen carrier were investigated, focusing on the redox reactivity under different oxygen concentrations of $\mathrm{Cu}_{x} \mathrm{Mn}_{3-x} \mathrm{O}_{4} \leftrightharpoons \mathrm{Cu}_{x} \mathrm{Mn}_{2-x}+\mathrm{O}_{2}(\mathrm{~g})$. The oxygen transport capacity of this type of oxygen carrier was determined as $0.0463 \mathrm{~g} \mathrm{O}_{2} / \mathrm{g}$ oxygen carrier. With an increase in the oxygen concentration $(0.001-50 \%)$ in the carrier gas, the required oxygen uncoupling temperature increases $\left(625.5-921{ }^{\circ} \mathrm{C}\right)$. Based on relationship between initial reduction temperature and equilibrium oxygen concentration, the following thermodynamic characteristics of the redox reaction were obtained: $\Delta G=-0.119 T+150.41 \mathrm{~kJ} / \mathrm{mol}$ and $K_{p}=\exp (14.31-18090.8 / T)$. Compared to a Cu-based oxygen carrier, the reduction temperature is significantly reduced and the equilibrium oxygen concentration at the same reaction temperature is greatly increased. The redox reactivity under different heating rates and reaction temperatures were also investigated, and the results show that both the reduction and oxidation reactions are temperature driven at the considered temperatures. The reduction and oxidation kinetic models were established by the isoconversional method. When the relative conversion $X<0.5$, the reduction of the Cu-Mn oxygen carrier follows a shrinking core model $(n=3)$, and the oxidation follows a shrinking core model $(n=2)$. When $X \geq 0.5$, the reduction proceeds according to a one-dimensional diffusion model, whereas the oxidation follows a shrinking core model $(n=3)$.
\end{abstract}

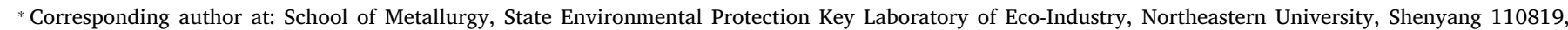
China.

E-mail addresses: wangkun@mail.neu.edu.cn, k.wang@tue.nl (K. Wang). 


\section{Introduction}

Chemical-looping (CL) uses a versatile and reversible gas-solid redox reaction to control the reduction-oxidation process and has been getting more and more attention over the last years. At present, the chemical looping concept has been proposed for a variety of processes, such as chemical-looping combustion (CLC), chemical-looping with oxygen uncoupling (CLOU), chemical-looping gasification (CLG), chemical-looping hydrogen generation (CLHG), chemical-looping reforming (CLR) and chemical-looping air separation (CLAS) [1-6]. The use of lattice oxygen in the oxygen carrier is the common characteristic of the above chemical looping technologies. Certainly, the oxygen carrier is one of the key factors in the development of CL technologies and the oxygen carrier should have a high reactivity, high oxygen transport capacity, high stability against sintering, high mechanical strength, low cost, and should be environmentally friendly [7]. Cubased, Mn-based, Co-based, Fe-based, Ni-based, Ce-based and perovskite oxides are common oxygen carriers used in CL technologies [8-12].

In CL technologies, there are two ways to use the lattice oxygen: i) oxygen carriers directly react with the reactants; ii) oxygen carriers firstly release oxygen and subsequently the gas phase oxygen reacts with the reactants. For the latter, the oxygen carrier used should exhibit oxygen uncoupling activity, and it has an added benefit of increasing reaction rates compared to solid-solid reactions in case solid reactants, such as coal or biomass, are used, and this is known as CLOU technology [13]. A schematic of the CLOU process is shown in Fig. 1. Because the slow gasification reaction between solid fuel and oxygen carrier is replaced by the direct combustion of released oxygen and solid fuel, the reaction rates and thereby the solid fuel conversions are greatly increased. Moreover, the combustion of fuel consumes the oxygen released by oxygen carriers and it decreases the system oxygen partial pressure, increasing the oxygen uncoupling rate of oxygen carriers $[14,15]$. However, for the current CLOU technology, the separation of the oxygen carrier and ash, the carbon deposition on the oxygen carrier surface, and the power consumption of the oxygen carrier cycle are inevitable shortcomings. Separation of oxygen uncoupling and combustion reactions into two separated reactors maybe a solution of the above shortcomings. Fig. 2 shows a schematic of the interconnected CLOU system. It consists of three reactors, designated as the fuel reactor, oxidation reactor and reduction reactor. The reduction and oxidation reactors can be designed as fixed-bed reactors to decrease the power consumption circumventing the need for separating solid particles from carrier gases. The reduction and oxidation units are also known as CLAS, a CL technology proposed to produce pure oxygen or oxygen-enriched gases with features of high energy efficiency, simple operation and relative low cost $[16,17]$.

Unlike the immediate consumption of the oxygen released by the fuel in the CLOU process, in the interconnected CLOU process, the released oxygen is carried out of the reduction reactor by the carrier gases. Thus, the oxygen carrier needs to release oxygen at different oxygen concentrations, since the oxygen concentration in the carrier gases increases gradually from bottom to top of reactor. Moreover, the oxygen concentration in the outlet gas should be high enough to ensure a high efficiency of the combustion in the fuel reactor [18]. An oxygen carrier with the oxygen uncoupling activity is the basis for the CLOU technology, while the oxygen releasing capability into an atmosphere of relatively high oxygen concentration is key for the CLAS process. CuO is one of the most common oxygen carriers used for CL technologies due to its high oxygen transport capacity $\left(0.1 \mathrm{~g} \mathrm{O}_{2} / \mathrm{g} \mathrm{CuO}\right)$, high reactivity and low cost [19-21]. Above all, it has oxygen uncoupling activity, known as the redox reaction of copper oxides (Eq. (1)).

$4 \mathrm{CuO} \leftrightharpoons 2 \mathrm{Cu}_{2} \mathrm{O}+\mathrm{O}_{2}(\mathrm{~g})$

Table 1 shows the equilibrium oxygen concentration (EOC) of this redox reaction at different temperatures [8]. It can be seen that the reduction temperatures for $\mathrm{CuO}$ are high. However, the sintering of $\mathrm{Cu}$ based oxygen carriers is very serious at high temperatures due to the low melting points of copper oxides $\left(1450{ }^{\circ} \mathrm{C}\right.$ for $\mathrm{CuO}, 1235{ }^{\circ} \mathrm{C}$ for $\mathrm{Cu}_{2} \mathrm{O}$ and $1075{ }^{\circ} \mathrm{C}$ for $\mathrm{CuO}_{-} \mathrm{Cu}_{2} \mathrm{O}$ ) [22]. In order to increase the anti-sintering property, a variety of supports had been added during the preparation of Cu-based oxygen carriers. Wang et al. found that $\mathrm{Cu}$-based oxygen carriers with $60 \mathrm{wt} \% \mathrm{ZrO}_{2}$ and $50 \mathrm{wt} \% \mathrm{MgAl}_{2} \mathrm{O}_{4}$ as supports showed good stability against sintering at $1000{ }^{\circ} \mathrm{C}[15,23]$. Adánez-Rubio et al. investigated the mechanical stability, attrition rate and oxygen uncoupling behaviour of Cu-based oxygen carriers using a mixture support and found that oxygen carriers with a mixture support of $\mathrm{MgAl}_{2} \mathrm{O}_{4}$ / $\mathrm{TiO}_{2}, \mathrm{MgAl}_{2} \mathrm{O}_{4} / \mathrm{SiO}_{2}$ and $\mathrm{TiO}_{2} / \mathrm{SiO}_{2}$ all had good anti-sintering behavior at tested temperatures of $900-950{ }^{\circ} \mathrm{C}$ [24]. Cabello carried out long-lasting tests for a $\mathrm{Cu}_{14} \gamma \mathrm{Al}$ oxygen carrier and found that this type of oxygen carrier also showed excellent anti-sintering behaviour at $900{ }^{\circ} \mathrm{C}$ [25]. The anti-sintering property and cyclic stability of Cu-based oxygen carriers can be greatly improved with the addition of supports, and the reactivity of copper oxides was also improved after adding supports [26]. The supports reduce the activation energy and accelerate the reaction rate of the redox reaction of copper oxides. However, they do not change the thermodynamic characteristics of the redox reaction. At the highest testing temperature reported in the literature of $1000{ }^{\circ} \mathrm{C}$, the EOC is only $12.39 \%$, which is much lower than the oxygen concentration in air (21\%) [8]. Thus, the improvement of the thermodynamic properties of oxygen carriers, i.e. a decrease in the oxygen uncoupling temperature and an increase in the EOC of the redox reaction is key for the further development of the CLAS technology.

The thermodynamic properties of oxides can be effectively improved by elemental composition or substitution. Hou et al. used Ti and Dy elements to substitute the $\mathrm{Y}$ element in $\mathrm{YBaCo}_{4} \mathrm{O}_{7+\delta}$, and found that not only the initial oxygen uncoupling temperature decreased, but also the oxygen transport capacity increased after substitution [27]. The composite oxygen carriers of Mn-Si, Mn-Ni, Mn-Fe, Mn-Ca, Mn-Cu, Mn$\mathrm{Mg}$ were prepared to overcome the thermodynamic hindrance of the oxidation of $\mathrm{Mn}_{3} \mathrm{O}_{4}$ to $\mathrm{Mn}_{2} \mathrm{O}_{3}$, and by the elemental composition

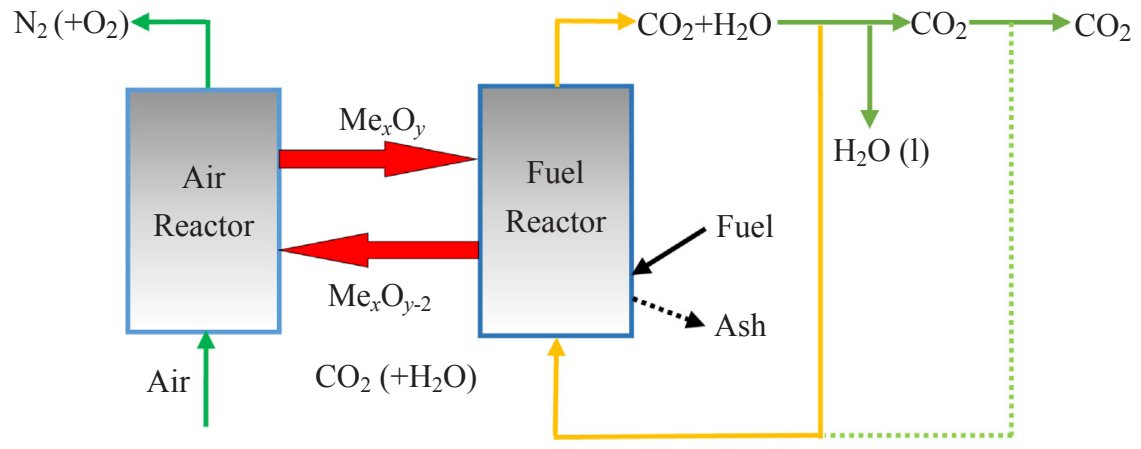

Fig. 1. Schematic view of CLOU. 


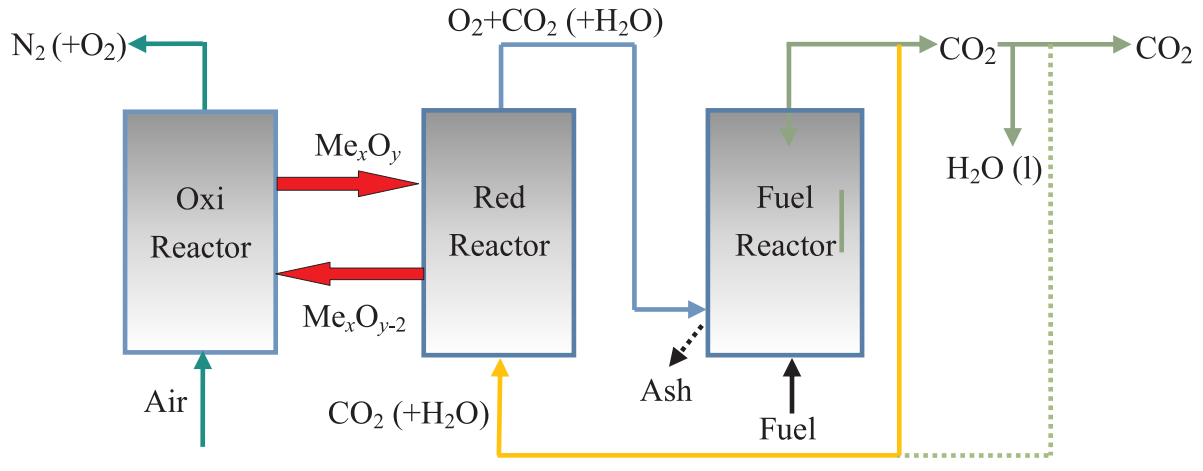

Fig. 2. Schematic view of interconnected CLOU.

Table 1

Equilibrium oxygen concentration at different temperatures.

\begin{tabular}{|c|c|c|c|c|c|c|c|c|c|c|c|}
\hline$T\left({ }^{\circ} \mathrm{C}\right)$ & 850 & 875 & 900 & 925 & 950 & 975 & 1000 & 1025 & 1050 & 1075 & 1100 \\
\hline EOC (\%) & 0.46 & 0.84 & 1.51 & 2.65 & 4.53 & 7.57 & 12.39 & 19.87 & 31.29 & 48.41 & 73.64 \\
\hline
\end{tabular}

method, the composite Mn-based oxygen carriers exhibited satisfying thermodynamic properties [28-30]. Pour et al. found that combined $\mathrm{CuO}$ and $\mathrm{Mn}_{3} \mathrm{O}_{4}$ oxides with 5, 10, 20, 31, and $61 \mathrm{wt} \% \mathrm{CuO}$ all could release gas-phase $\mathrm{O}_{2}$ in concentrations up to $1 \%$ at $750{ }^{\circ} \mathrm{C}$ [31]. Moghtaderi found that $\mathrm{Mn}$-Co composites changed the equilibrium partial pressure of oxygen in the system, and played a role in regulating the temperature range of the oxygen uncoupling reaction [16]. Driessens and Rieck suggested that $\mathrm{Cu}-\mathrm{Mn}$ composite oxygen carriers could reduce the uncoupling temperature and improve the oxidative regeneration ability of pure Mn-based oxygen carriers through analyzing the redox equation of Cu-Mn oxides by phase diagram [32]. The current researches confirmed that the Cu-Mn composite oxygen carrier could release oxygen at relatively low temperature. However, detailed information on thermodynamic and kinetic characteristics of this type of oxygen carrier is rare in literatures. The basic thermodynamic and kinetic data is significant to design the chemical looping system and to determine the operation parameters.

Thus, the main aim of this paper is to obtain the thermodynamic and kinetic characteristics of the Cu-Mn composite oxygen carrier. Firstly, a composite Cu-Mn oxygen carrier was prepared and characterized. Subsequently, the reduction and oxidation characteristics under different oxygen concentrations, heating rates and reaction temperatures were investigated by experimental methods. The Cu-Mn composite oxygen carrier showed satisfying oxygen uncoupling properties and is considered as an excellent candidate for the CLAS. The reactivity as well as the oxygen transport capacity of this type of oxygen carrier was obtained. Thermodynamic data of the redox reaction, viz. the Gibbs free energy change $(\Delta G)$ and the equilibrium oxygen concentration (EOC) or equilibrium constant $\left(K_{\mathrm{p}}\right)$ were determined. The kinetic models of the reduction and oxidation reactions were established using the isoconversional (model-free) method. This research supplies the basic thermodynamic and kinetic data of the Cu-Mn composite oxygen carrier, which is very important for the advancement of this type of oxygen carrier.

\section{Experimental section}

\subsection{Preparation of the composite oxygen carrier}

For all of the oxygen carriers preparation methods, firstly precursors were prepared, which were subsequently calcined to increase their strength. Mechanical mixing is one of the most commonly applied methods to prepare the precursor. This method is simple, low-cost with high yield. $\mathrm{ZrO}_{2}$ was used as the support to decrease the sintering propensity. Graphite was used as the pore forming agent, which was totally consumed during the calcination process [33]. Raw materials of commercial particles of $\mathrm{CuO}(\geq 99.0 \%), \mathrm{Mn}_{2} \mathrm{O}_{3}$ (99.9\%), $\mathrm{ZrO}_{2}$ ( $\geq 99.0 \%$ ) with mole ratio of $\mathrm{CuO}: \mathrm{Mn}_{2} \mathrm{O}_{3}: \mathrm{ZrO}_{2}=1.5: 1: 1$ and graphite (10 wt\%) were mixed fully and deionized water was added to the mixture to form a paste. Subsequently the paste was squeezed to the precursor with a cylindrical shape and dried for $12 \mathrm{~h}$ at $80{ }^{\circ} \mathrm{C}$ and calcined for $6 \mathrm{~h}$ at $950{ }^{\circ} \mathrm{C}$. After sieving, particles with a size range of $150-180 \mu \mathrm{m}$ were obtained for the experiments.

\subsection{Characterization of the composite oxygen carrier}

The improvement of the oxygen uncoupling properties of a $\mathrm{CuO}$ $\mathrm{Mn}_{2} \mathrm{O}_{3}$ composite oxygen carrier results from the formation of a new active phase. Thus, it is important to determine the active species in the oxidized and reduced samples. X-ray diffraction (XRD, Panalytieal PW 3040/60) measurement was carried out to identify the crystalline chemical species. The XRD patterns (10-90 rad) were collected with $\mathrm{Cu}$ $\mathrm{K}-\alpha$ working at $30 \mathrm{kV}$ and $40 \mathrm{~mA}$ with steps of $0.017 \mathrm{rad} / \mathrm{s}$. Fig. 3 shows the XRD patterns of the $\mathrm{Cu}-\mathrm{Mn}$ composite oxygen carrier. The active phases in the oxidized sample are $\mathrm{Cu}_{x} \mathrm{Mn}_{3-x} \mathrm{O}_{4}$ (including $\mathrm{Cu}_{1.4} \mathrm{Mn}_{1.6} \mathrm{O}_{4}, \mathrm{Cu}_{1.5} \mathrm{Mn}_{1.5} \mathrm{O}_{4}$ and $\mathrm{CuMn}_{2} \mathrm{O}_{4}$ ). After reduction, the active phases in the reduced sample are $\mathrm{Cu}_{x} \mathrm{Mn}_{2-x} \mathrm{O}_{2}$ (including $\mathrm{CuMnO}_{2}$ and $\left.\mathrm{Cu}\left(\mathrm{Cu}_{0.04} \mathrm{Mn}_{0.96} \mathrm{O}_{2}\right)\right)$. The $\mathrm{ZrO}_{2}$ support is visible in the oxidized and reduced samples and it does not react with the active phases. The phases of $\mathrm{CuO}\left(\mathrm{Cu}_{2} \mathrm{O}\right)$ and $\mathrm{Mn}_{2} \mathrm{O}_{3}\left(\mathrm{Mn}_{3} \mathrm{O}_{4}\right)$ are not found in the oxidized and reduced oxygen carriers, concluding that the active phases are only the composite oxides of copper and manganese and the redox reaction of the Cu-Mn composite oxygen carrier can be represented by:

$\mathrm{Cu}_{x} \mathrm{Mn}_{3-\mathrm{x}} \mathrm{O}_{4} \rightleftharpoons \mathrm{Cu}_{x} \mathrm{Mn}_{2-\mathrm{x}} \mathrm{O}_{2}+\mathrm{O}_{2}(\mathrm{~g})$

Subsequent measurements of the specific surface area (BET), surface structure-elemental distribution (SEM-EDX) and crushing strength of the composite oxygen carrier were performed on Quantachrome NOVA 1200e, ULTRA 55 and a press apparatus, respectively. Fig. 4 shows the SEM-EDX images of the composite oxygen carrier. The SEM images show that the shapes of the oxygen carrier particles are irregular, resulting from the agate mortar during the preparation. In addition, macrospores are observed and the surface morphology of the oxygen carrier shows a lose structure, which is beneficial for gas diffusion inside the oxygen carrier particles [34]. The elemental distribution of the oxygen carrier indicates that the $\mathrm{Cu}, \mathrm{Mn}$ and $\mathrm{O}$ elements are distributed 


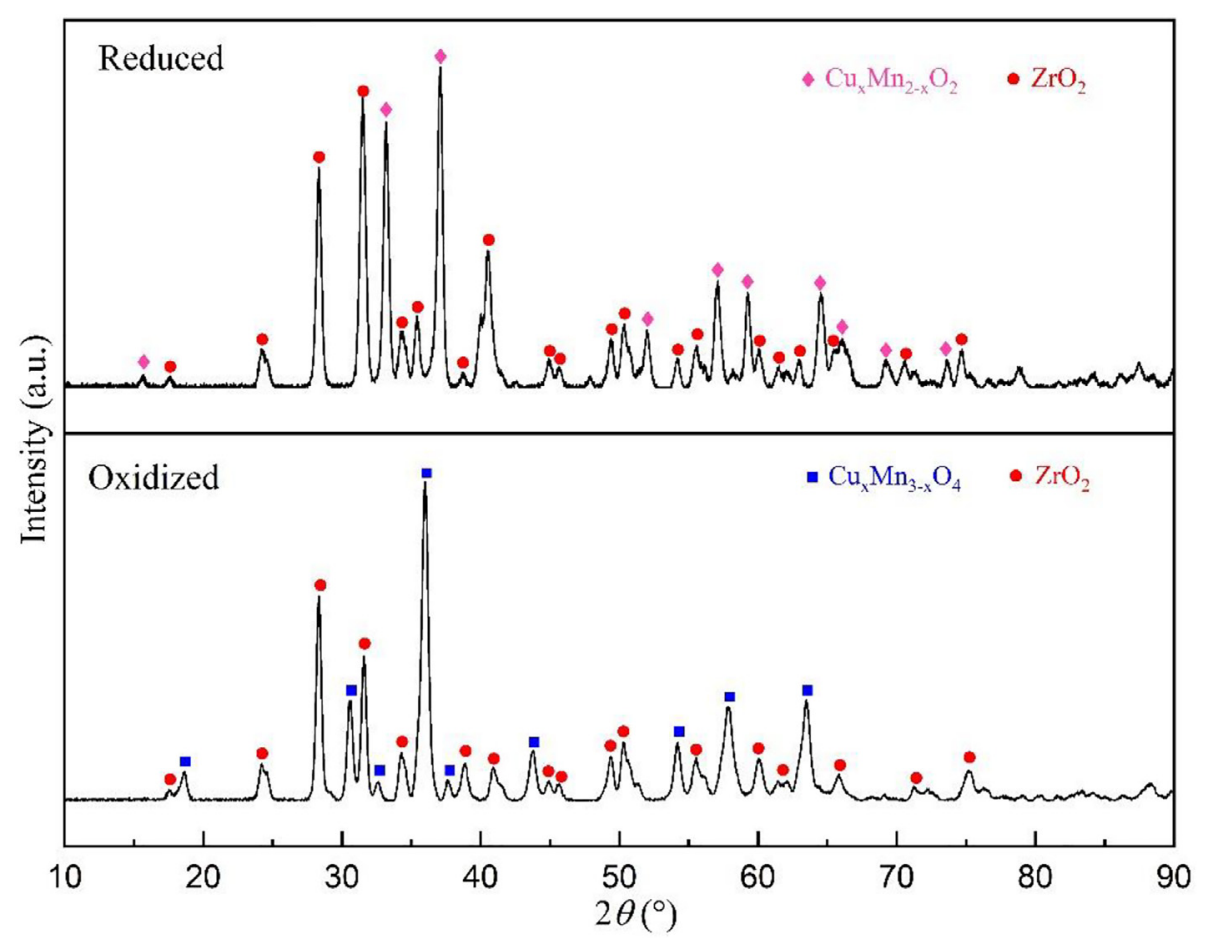

Fig. 3. Chemical compounds in reduced and oxidized Cu-Mn/Zr composite oxygen carrier.

uniformly. And the corresponding distribution of $\mathrm{Cu}, \mathrm{Mn}$ and $\mathrm{O}$ elements also indicates the formation of composite $\mathrm{Cu}-\mathrm{Mn}-\mathrm{O}$ oxides. The BET surface area of the composite oxygen carrier is only $0.215 \mathrm{~m}^{2} / \mathrm{g}$ due to the high-temperature calcination process and the formation of composite phases. This value of surface area is typical for oxygen carrier in CL technologies [35]. On the contrary, the crushing strength of the composite oxygen carrier is higher than $24 \mathrm{~N}$ and this value is high enough for application in circulating fluidized and packed beds [7]. Table 2 shows the characteristics of the Cu-Mn composite oxygen carrier.

\subsection{Experimental set-up}

Experiments were carried out in a thermogravimetric (TG) analyzer
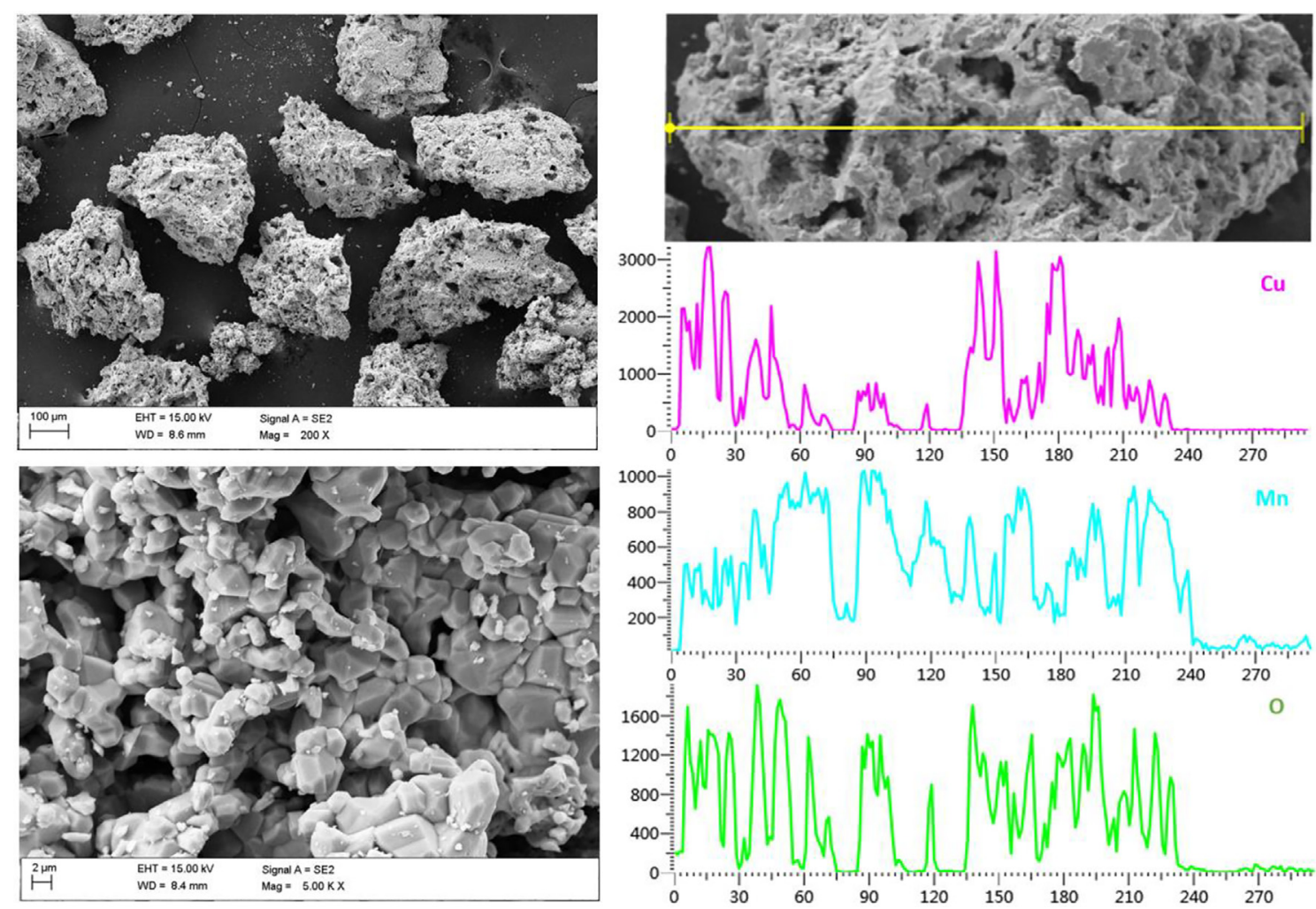

Fig. 4. SEM-EDX images of the Cu-Mn/Zr composite oxygen carrier. 
Table 2

Characteristics of Cu-Mn composite oxygen carrier.

\begin{tabular}{ll}
\hline Items & Cu-Mn composite OC \\
\hline Particle size $(\mu \mathrm{m})$ & $150-180$ \\
Phase composition & Reduced: $\mathrm{Cu}_{x} \mathrm{Mn}_{2-x} \mathrm{O}_{2}, \mathrm{ZrO}_{2}$ \\
& Oxidized: $\mathrm{Cu}_{x} \mathrm{Mn}_{3-x} \mathrm{O}_{4}, \mathrm{ZrO}_{2}$ \\
Support adding ratio $(w t . \%)$ & 31 \\
BET surface area $\left(\mathrm{m}^{2} / \mathrm{g}\right)$ & 0.215 \\
Crushing strength $(\mathrm{N})$ & $>24$
\end{tabular}

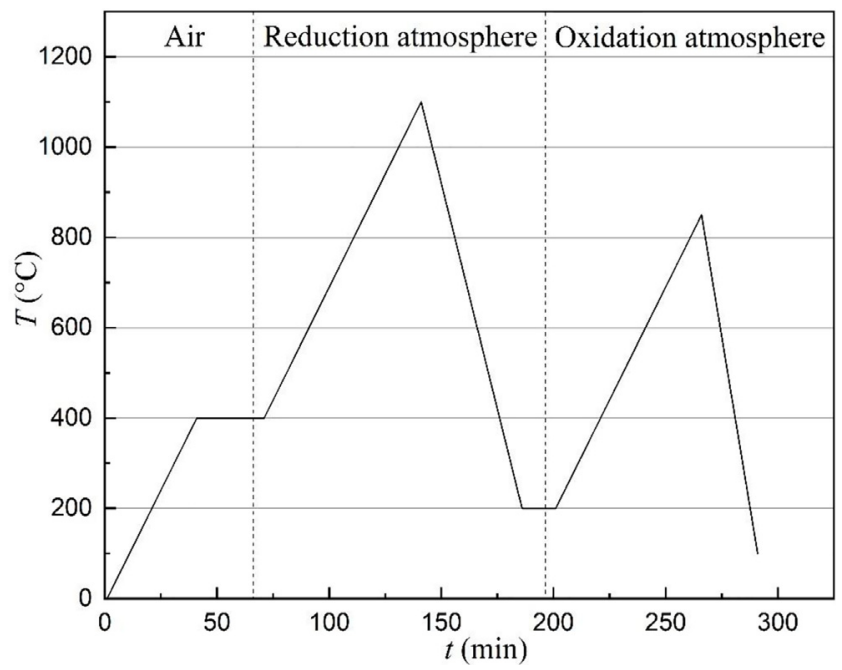

Fig. 5. Temperature program during the TGA experiments to determine the redox kinetics.

(NETZSCH, STA409 PC) and a packed-bed reactor. For TG experiments, in order to determine thermodynamic data, redox experiments under different oxygen concentrations in the carrier gases $(0 \%, 7 \%, 14 \%$, $21 \%, 33.3 \%, 50 \%$ for reduction and $14 \%, 21 \%, 33.3 \%$ for oxidation) were carried out. In order to determine the kinetic data, experiments under different heating rates $(10,15,20,25 \mathrm{~K} / \mathrm{min})$ were carried out. Experiments under $900{ }^{\circ} \mathrm{C}$ reduction $\left(\mathrm{N}_{2}\right.$ atmosphere) and $700{ }^{\circ} \mathrm{C}$ oxidation (air atmosphere) temperatures were also carried out to determine the oxygen transport capacity. Each TG experiment contains a continuous reduction-oxidation process. Fig. 5 shows a diagram of the temperature program for TG experiments. Packed-bed experiments were set-up (Fig. 6) and the outlet gas phase compositions were measured using an online gas analyzer. The reduction ( $\mathrm{N}_{2}$ atmosphere) and oxidation (air atmosphere) temperatures were determined as $850-950{ }^{\circ} \mathrm{C}$ and $650-750{ }^{\circ} \mathrm{C}$ with a temperature interval of $25{ }^{\circ} \mathrm{C}$.

\subsection{Data evaluation}

In each TG experiment, the conversion of the oxygen carrier was calculated by Eqs. (3) and (4):

$X_{\text {red }}=\frac{m_{\text {oxi }}-m}{m_{\text {oxi }}-m_{\text {red }}}$

$X_{o x i}=\frac{m-m_{\text {red }}}{m_{\text {oxi }}-m_{\text {red }}}$

where $X_{\text {red }}$ and $X_{\text {oxi }}$ are the reduction and oxidation conversion; $m_{\text {red }}$ and $m_{\text {oxi }}$ represent the sample mass of the fully reduced and oxidized samples, mg; and $m$ is the actual mass at each time step during the test, mg.

\section{Results and discussion}

\subsection{Reactivity of the composite oxygen carrier}

Isothermal TG experiments under fixed reduction and oxidation temperatures were carried out and the mass changes and mass change rates are shown in Fig. 7. During the experiment, $10 \mathrm{mg}$ sample was used with a volumetric flow rate of $30 \mathrm{ml} / \mathrm{min}$. The mass loss in reduction process is almost the same as the mass gain in oxidation process. The reduced oxygen carrier can be fully oxidized and this type of oxygen carrier presents excellent reduction-oxidation property. Except for $\mathrm{N}_{2}$ and $\mathrm{O}_{2}$, there is no other gas composition in carrier gases. Thus,

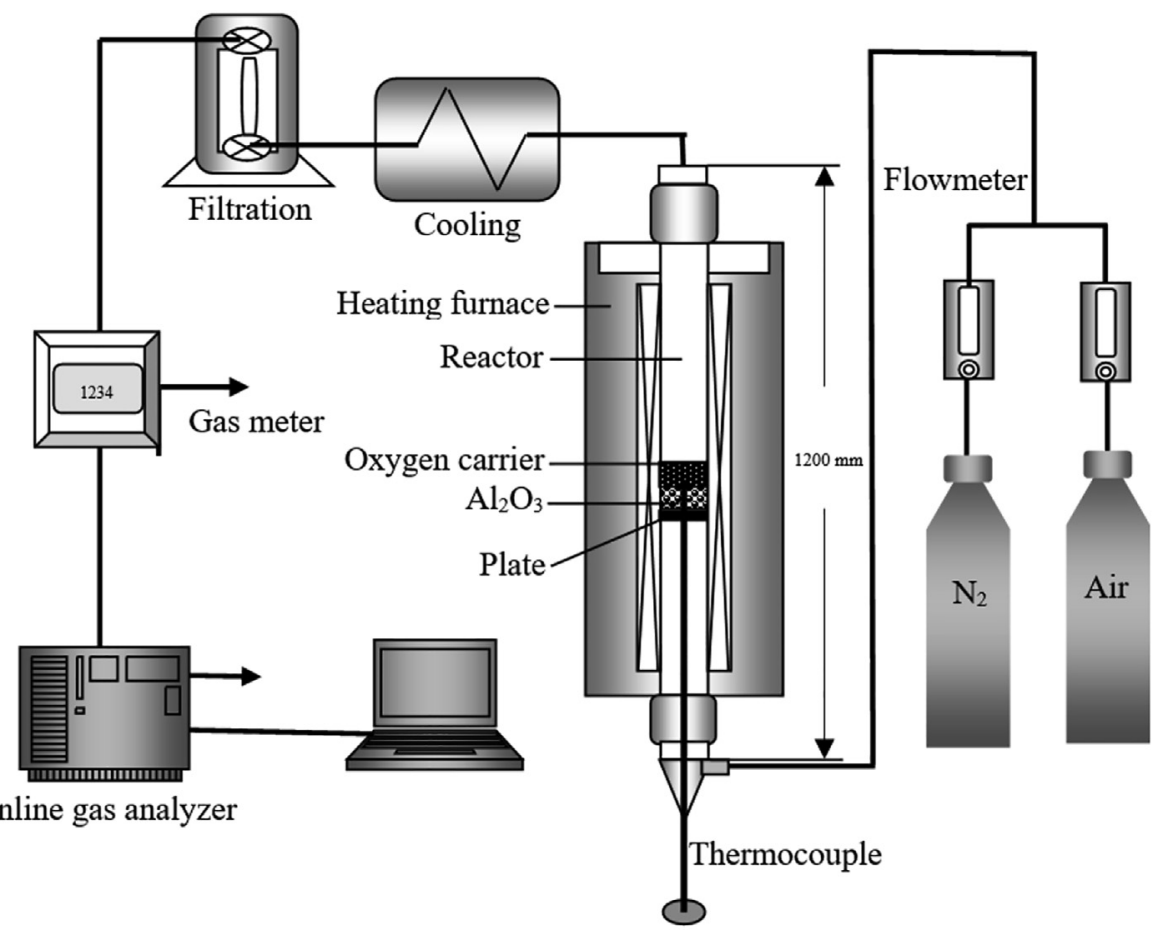

Fig. 6. The diagram of packed-bed system. 


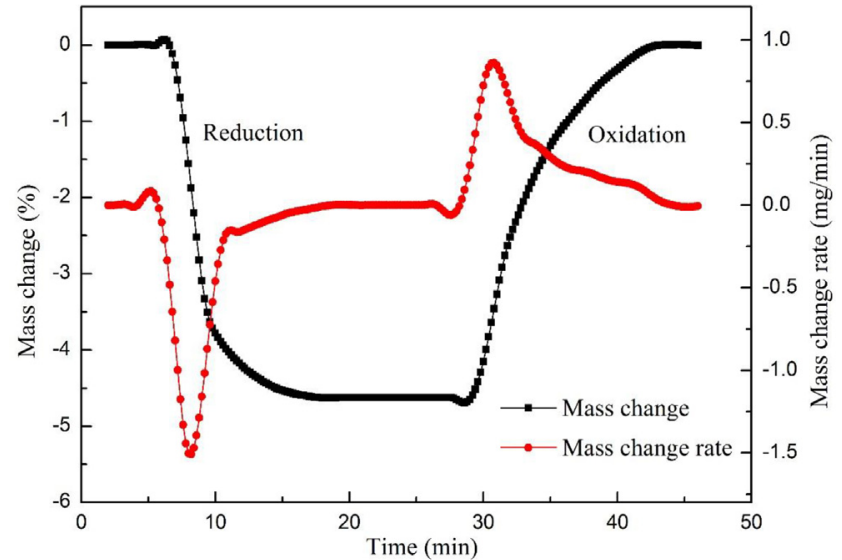

Fig. 7. Mass changes and mass change rates during the reduction-oxidation process.

the mass changes of samples are only caused by the redox reaction of oxygen carrier. These results are corresponding to the phase composition analysis in Fig. 3. The phases of this oxygen carrier transfer between $\mathrm{Cu}_{x} \mathrm{Mn}_{3-x} \mathrm{O}_{4}$ and $\mathrm{Cu}_{x} \mathrm{Mn}_{2-x} \mathrm{O}_{2}$ during the reduction-oxidation process. The maximum mass loss is $-4.63 \%$ and the oxygen transport capacity of this type of oxygen carrier is determined as $0.0463 \mathrm{~g} \mathrm{O}_{2} / \mathrm{g}$ oxygen carrier. In addition, the reduction rate is higher than oxidation rate due to the higher reaction temperature.

Further, the outlet gas phase compositions in a packed-bed reactor were also measured to confirm the oxygen released or absorbed by the composite oxygen carrier. Fig. 8 shows the outlet oxygen concentrations measured during the reduction-oxidation process. In the reduction process, the outlet oxygen concentrations at different reduction temperatures all have a downward trend in the initial stage of the reaction. However, as the reaction proceeds, the curves of the outlet oxygen concentration show some inflection points comparing to the comparative experiment (operating at room temperature), which indicates that the composite oxygen carrier starts releasing oxygen at these points. In addition, when the reaction temperature is higher, the oxygen concentration at the inflection point is higher. This is explained by the fact that the composite oxygen carrier starts releasing oxygen when the oxygen concentration around the oxygen carrier particles is below the equilibrium oxygen concentration, and the oxygen equilibrium partial pressure of the oxygen-releasing reaction increases as the reduction temperature increases. In the oxidation process, the oxygen concentrations show a creeping increase compared to the comparative experiment, which indicates the reduced oxygen carrier absorbs some oxygen from air. Moreover, at the same reaction time, the oxidation rates decrease with an increase in the oxidation temperature. When the oxygen concentration in the inlet carrier gas is constant $(21.0 \%)$, a higher reaction temperature leads to a higher oxygen equilibrium partial pressure and a lower driving force for the oxidation reaction. In the following part, the oxygen equilibrium partial pressure or equilibrium oxygen concentration will be determined.

\subsection{Determination of thermodynamic characteristic}

Temperature programmed experiments under different oxygen concentrations were carried out and the changes of the reduction and oxidation conversions with temperature are shown in Fig. 9. As the oxygen concentration in the carrier gas increases, the starting and ending temperatures of the reduction reaction increase. The explanation is that the driving force for the reduction reaction is the difference between the EOC and the actual oxygen concentration in the carrier gas. When the EOC is higher than the oxygen concentration in the carrier gas, the oxygen uncoupling of the oxygen carrier starts [36]. In
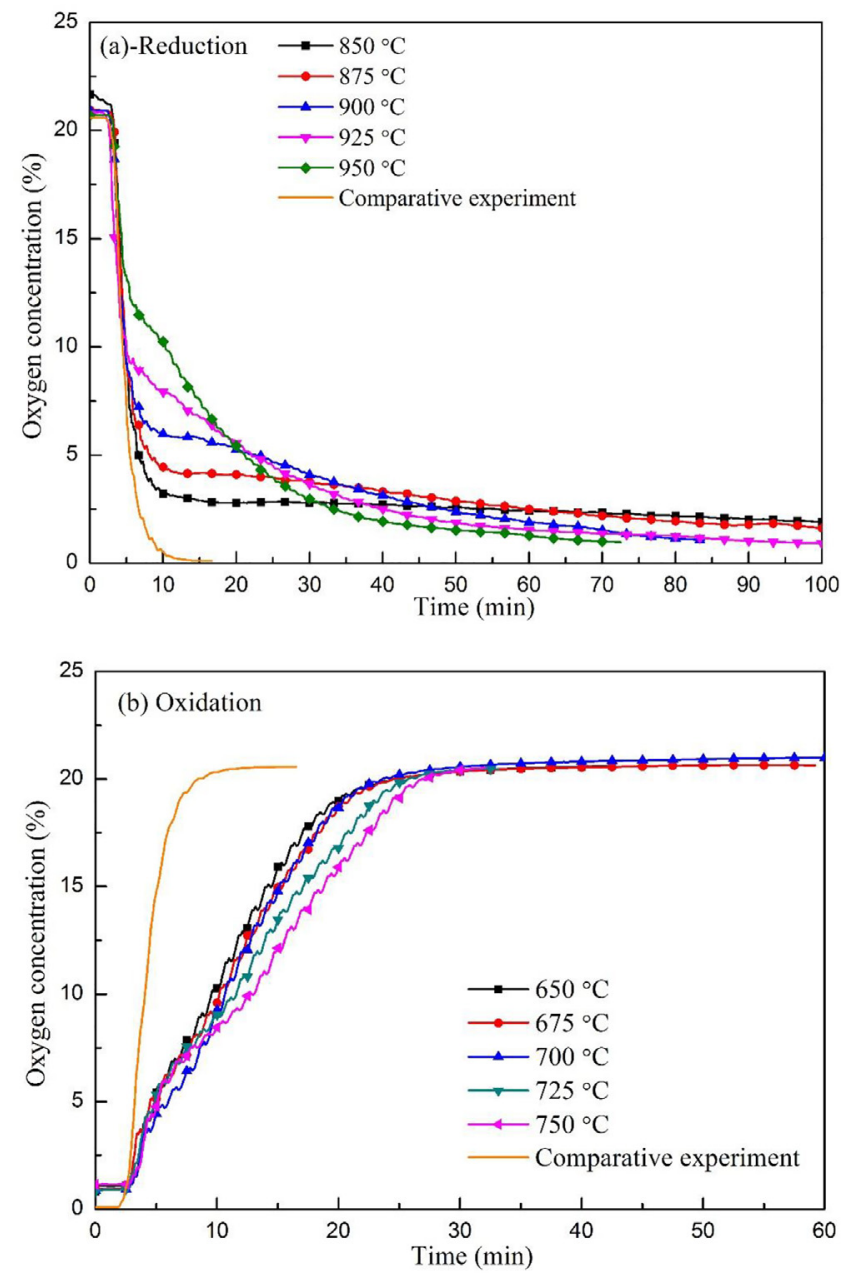

Fig. 8. Outlet oxygen concentrations measured during the reduction-oxidation process.

each experiment, the gas flow rate is large enough that the amount of oxygen released by the oxygen carrier does not affect the local oxygen concentration. Thus, the EOC at the starting temperature of the reduction is the same as the oxygen concentration in the carrier gas. Table 3 shows the corresponding relation of the starting temperature and the EOC. The reduction conversion curves are S-shaped, which indicates that the driving force goes through a slow increase followed by a fast increase with increasing of temperature. The effects of the oxygen concentration on the oxidation reaction rate are small. The explanation is that at low reaction temperatures, the EOC is very low (near zero), so that for all tested oxygen concentrations, the driving force for oxidation is large enough. Thus, the oxidation processes under different oxygen concentrations in the carrier gas are very similar.

Based on the experimental data, the $\Delta G$ and EOC of the redox reaction are determined. The Gibbs free energy $(G)$ of a matter is the state function and the $\Delta G$ of a reaction can be calculated by subtracting the $G$ of reactants from the $G$ of the products $[8,37]$ :

$\Delta G=\Delta G_{\text {Products }}-\Delta G_{\text {Reactants }}$

$G$

$$
\begin{aligned}
= & \sum_{\text {ideal gas }} n_{i}\left(g_{i}^{0}+R T \ln P_{i}\right)+\sum_{\text {condensed }}^{\text {phases }} \\
& \sum_{\text {solution-1 }} n_{i} g_{i}^{0}+ \\
& \left(g_{i}^{0}+R T \ln X_{i}+R T \ln \gamma_{i}\right)+\sum_{\text {solution-2 }} n_{i} \\
&
\end{aligned}
$$

where $n_{i}$ is the number of moles of component $i$, mol; $P_{i}$ is the 

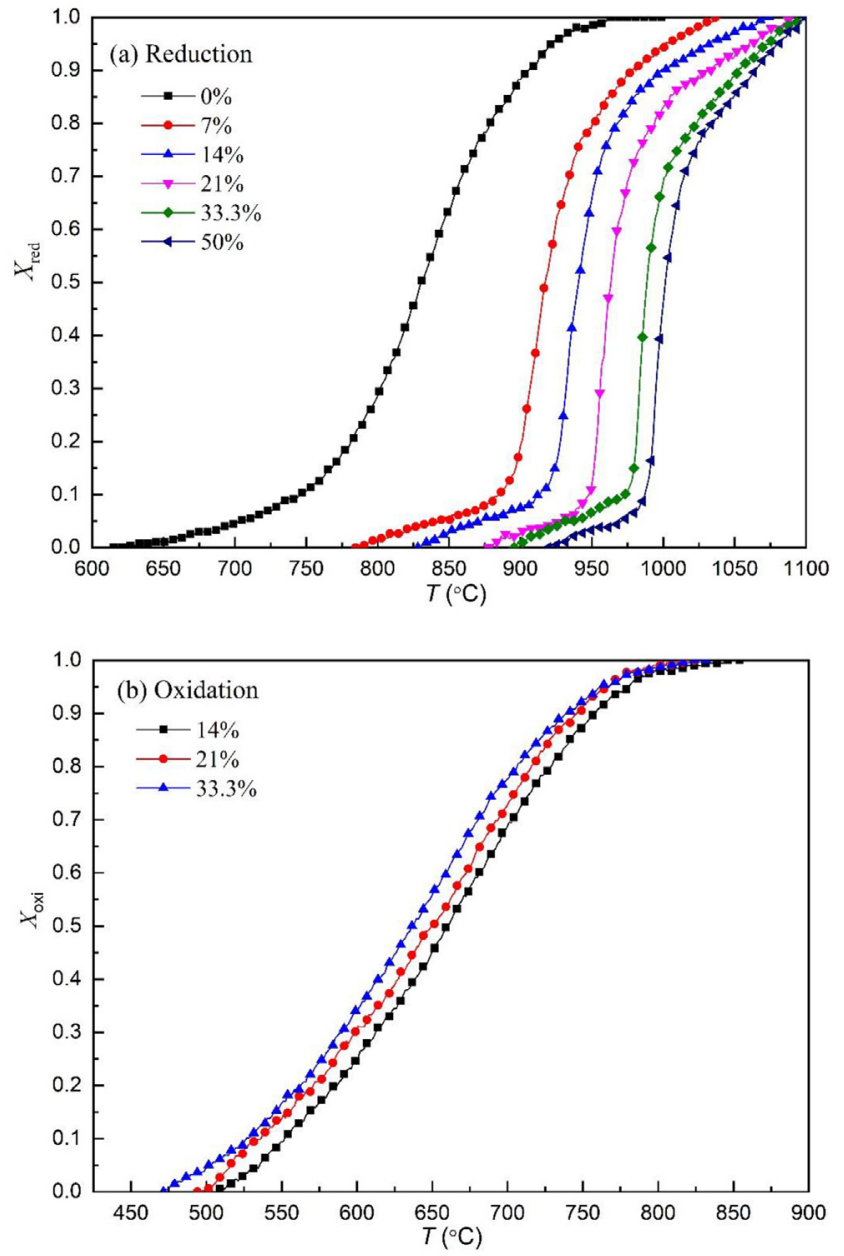

Fig. 9. Changes in reduction and oxidation conversions under different oxygen concentrations.

Table 3

Starting temperatures for the oxygen uncoupling at different EOCs.

\begin{tabular}{lllllll}
\hline EOC $(\%)$ & 0.001 & 7 & 14 & 21 & 33.3 & 50 \\
\hline$T\left({ }^{\circ} \mathrm{C}\right)$ & 625.5 & 786.5 & 835 & 878 & 897 & 921 \\
\hline
\end{tabular}

equilibrium partial pressure of component $i$ in the gas, Pa; $X_{i}$ is the mole ratio fraction of component $i ; \gamma_{i}$ is the activity coefficient of component $i$; $g_{i}$ is the standard Gibbs free energy of component $i, \mathrm{~J} / \mathrm{mol} ; T$ is the temperature, $\mathrm{K} ; R$ is the universal gas constant, $8.314 \mathrm{~J} /(\mathrm{mol} \cdot \mathrm{K})$.

The reduction and oxidation of the oxygen carrier is a reversible process and the equilibrium constant $(K)$ at different temperatures can be calculated:

$K=\exp (-\Delta G / R T)$

For a reaction involving gases (Eq. (8)), the equilibrium constant is the pressure equilibrium constant $\left(K_{\mathrm{p}}\right)$ and it can be calculated by Eq. (9).

$a \mathrm{~A}(g)+b \mathrm{~B}(g) \leftrightharpoons c \mathrm{C}(g)+d \mathrm{D}(g)$

$K_{P}=\frac{P_{C}^{c} P_{D}^{d}}{P_{A}^{a} P_{B}^{b}}$

where $P_{\mathrm{A}}, P_{\mathrm{B}}, P_{\mathrm{C}}$ and $P_{\mathrm{D}}$ are the relative pressures of components A, B, C and $D$ respectively.

For the reduction reaction of Cu-Mn composite oxygen carrier (Eq. (2)), $K_{\mathrm{p}}$ equals the value of equilibrium oxygen concentration (EOC).

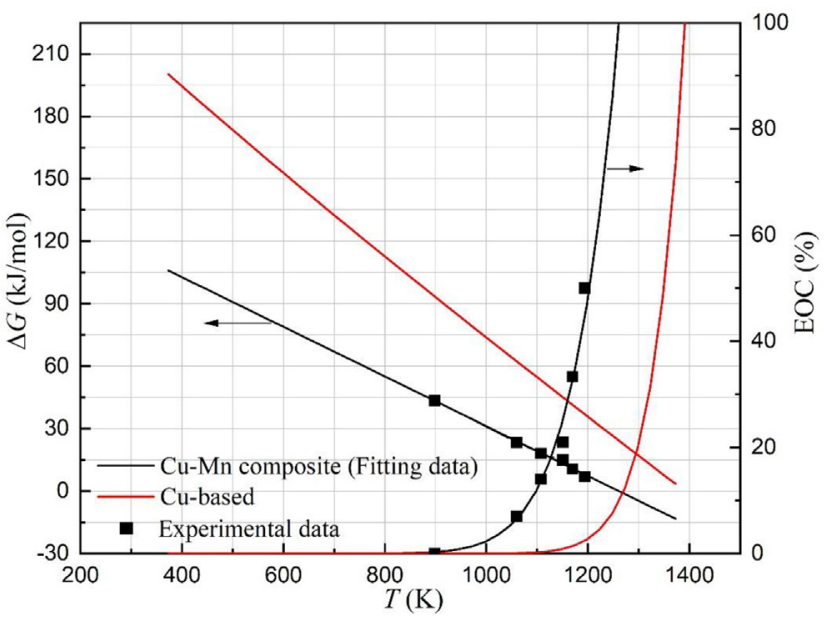

Fig. 10. Values of $\Delta G$ and EOC of Cu-Mn and $\mathrm{Cu}$ oxygen carriers at different temperatures.

Thus, the relationship of $\Delta G$ and EOC can be described as follows:

$K_{P}=\mathrm{EOC}=\exp (-\Delta G / R T)$

Yielding a direct relation of the temperature ( $T$ ) and EOC.

$\Delta G=-0.119 T+150.41, \mathrm{~kJ} / \mathrm{mol}$

Yielding for $K_{\mathrm{p}}$ as a function of temperature:

$K_{p}=\exp (-\Delta G / R T)=\exp (14.31-18090.8 / T)$

Fig. 10 shows the values of $\Delta G$ and EOC of the composite Cu-Mn oxygen carrier as a function of temperature. Compared to a $\mathrm{Cu}$-based oxygen carrier, the starting reduction temperature decreases, or alternatively the values of the EOC at the same reaction temperature increases greatly $[18,23,38]$. At $1264 \mathrm{~K}$, the EOC of Cu-Mn composite oxygen carrier is $100 \%$ and pure oxygen could be produced at this temperature.

\subsection{Establishment of kinetic models}

In addition to thermodynamic data, the kinetics of redox reactions of oxygen carrier is important for the design and optimization of the reactor $[39,40]$. Temperature programmed experiments with heating rates of $10,15,20$ and $25 \mathrm{~K} / \mathrm{min}$ were carried out. Fig. 11 shows the changes in reduction and oxidation conversions at the respective temperature under different heating rates. For the reduction step, the starting temperature increases with an increase in the heating rate. This is due to the thermal hysteresis caused by heat transfer limitations from the surface to the core of the particles. However, for the oxidation, the differences in the starting temperatures under different heating rates are somewhat smaller, which is related to the exothermicity of the oxidation reaction, which is beneficial for heating of the oxygen carrier particles. For both the reduction and oxidation steps, the ending temperatures under different heating rates are almost the same. However, the time required when using a higher heating rate is less. Thus, the average reaction rate increases with an increase in the heating rate. This phenomenon shows that both the reduction and oxidation reactions are temperature driven in the tested temperature range.

Because the reduction of oxygen carrier is exothermic and the oxidation of oxygen carrier is endothermic, there is a temperature change of the sample during the reduction-oxidation process. Thus, the reduction and oxidation kinetic models for the Cu-Mn composite oxygen carrier were determined based on the temperature programmed experimental data and the isoconversional (model-free) method was used. In this method, the activation energy $(E)$ is obtained without an assumption on the exact mechanism and the activation energy does not 

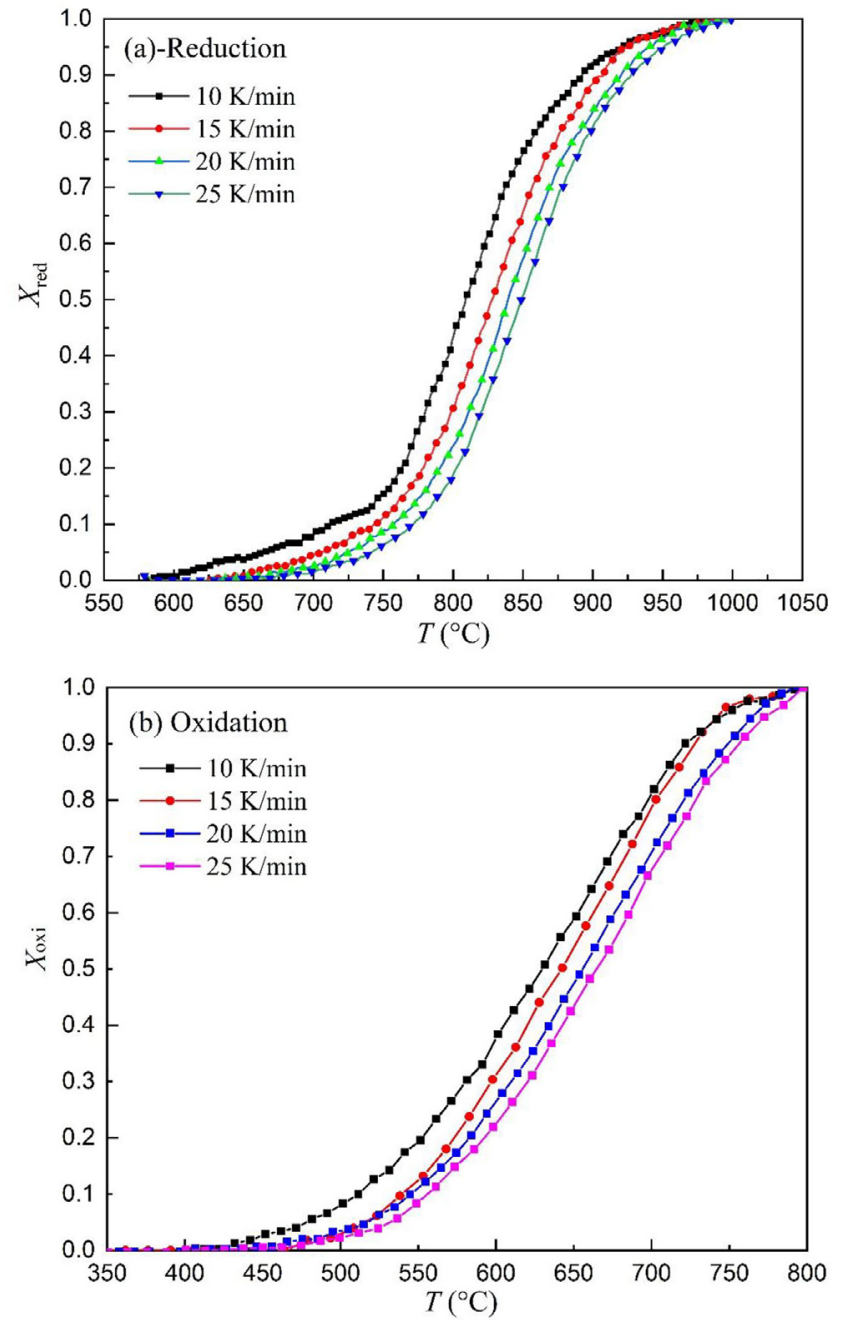

Fig. 11. Changes of reduction and oxidation conversions under different heating rates.

change with the heating rate. Similar as the other kinetic methods, this method is based on the basic gas-solid kinetic equation [36,41-43]:

$\frac{d X}{d t}=K(T) H(P) f(X)$

For temperature programmed conditions (using $\beta$ to denote the constant heating rate), the temperature-controlled rate term $K(T)$ can be expressed using Arrhenius equation with $A$ as the pre-exponential factor:

$K(T)=(A / \beta) \exp (-E / R T)$

The pressure-controlled rate term $H(P)$ can be expressed as:

Forthereductionstep: $H(P)=\frac{P_{e}-P_{0}}{P_{e}}$

Fortheoxidationstep: $H(P)=\frac{P_{0}-P_{e}}{P_{0}}$

where $P_{0}$ and $P_{\mathrm{e}}$ represent the oxygen pressure in the reactor and the equilibrium oxygen pressure of the redox reaction respectively, $\mathrm{Pa}$.

As mentioned before, the oxygen released by oxygen carrier does not affect the local oxygen pressure in the reactor because of the relatively high feed flow rate applied, so that during the reduction step, the oxygen carrier released its oxygen into a $\mathrm{N}_{2}$ atmosphere, whereas in the oxidation step, the oxygen carrier absorbed the oxygen in an air atmosphere. Thus, both for the reduction and oxidation steps, $H(P) \approx 1$.
The integration of Eq. (14) over temperature yields:

$$
\begin{aligned}
G(X) & =\int_{T_{0}}^{T}(A / \beta) \exp (-E / R T) d T \approx \int_{0}^{T}(A / \beta) \exp (-E / R T) d T \\
& =\frac{A E}{\beta R} \int_{u_{T}}^{\infty} \frac{-e^{-u}}{u^{2}} d u=\frac{A E}{\beta R} \cdot P(u)
\end{aligned}
$$

$P(u)=\int_{\mu_{T}}^{\infty} \frac{\exp (-\mu)}{\mu^{2}} d \mu$

$u=\frac{E}{R T}$

where the method by Starink provides an efficient way to obtain an accurate approximation to the solution of the integral in Eq. (18) [44-46]:

$P(\mu) \cong \frac{\exp (-1.0008 \mu-0.312)}{\mu^{1.92}}$

So that Eq. (17) can be rewritten as:

$\ln \frac{\beta}{T^{1.92}}=-1.0008 \frac{E}{R T}+C$

From Eq. (21), it can be concluded that the functional relationship between $\ln \left(\beta / T^{1.92}\right)$ and $1 / T$ is linear. Through linear fitting of the experimental data of $\ln \left(\beta / T^{1.92}\right)$ vs. $1 / T$, the activation energies were obtained from the slopes of the fitting lines at different conversions. Fig. 12 shows the fitted curves for conversions ranging from 0.2 to 0.8
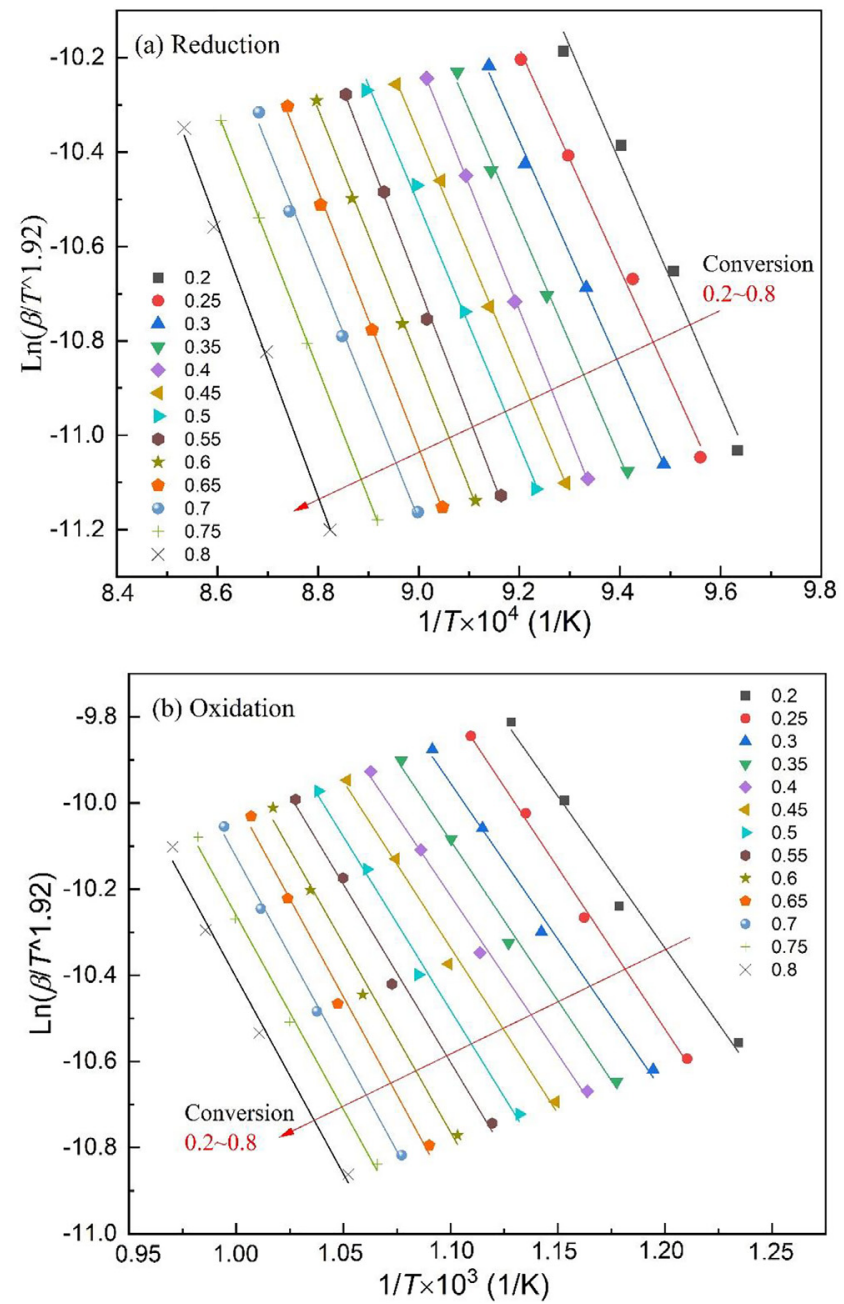

Fig. 12. Fitting lines at conversion of 0.2 to 0.8 for the reduction and oxidation reactions. 
Table 4

Common kinetic mechanism functions of solid-gas reaction.

\begin{tabular}{|c|c|c|c|c|}
\hline Nmuber & Code & Mechanism & Differential $f(X)$ & Integral $G(X)$ \\
\hline & $\mathrm{D}_{\mathrm{n}}$ & Diffusion & - & - \\
\hline 1 & $\mathrm{D}_{1}$ & 1-D diffusion & $(1 / 2) X^{-1}$ & $X^{2}$ \\
\hline 2 & $\mathrm{D}_{2}$ & 2-Ddiffusion & {$[-\ln (1-X)]^{-1}$} & $X+(1-X) \ln (1-X)$ \\
\hline 3 & $\mathrm{D}_{3}$ & 3-D diffusion(cylinder) & $(3 / 2)\left[(1-X)^{-1 / 3}-1\right]^{-1}$ & $1-(2 / 3) X-(1-X)^{2 / 3}$ \\
\hline 4 & $\mathrm{D}_{4}$ & 3-D diffusion(sphere) & $(3 / 2)(1-X)^{2 / 3}\left[1-(1-X)^{1 / 3}\right]^{-1}$ & {$\left[1-(1-X)^{1 / 3}\right]^{2}$} \\
\hline 5 & $\mathrm{D}_{5}$ & 3-D (Anti-Jander) & $(3 / 2)(1+X)^{2 / 3}\left[(1+X)^{1 / 3}-1\right]^{-1}$ & {$\left[(1+X)^{1 / 3}-1\right]^{2}$} \\
\hline 6 & $\mathrm{D}_{6}$ & 3-D (ZLT) & $(3 / 2)(1-X)^{4 / 3}\left[(1-X)^{-1 / 3}-1\right]^{-1}$ & {$\left[(1-X)^{-1 / 3}-1\right]^{2}$} \\
\hline 7 & $\mathrm{D}_{7}$ & 3-D (Jander) & $6(1-X)^{2 / 3}\left[1-(1-X)^{1 / 3}\right]^{1 / 2}$ & {$\left[1-(1-X)^{1 / 3}\right]^{1 / 2}$} \\
\hline \multirow[t]{2}{*}{8} & $\mathrm{D}_{8}$ & 2-D (Jander) & $(1-X)^{1 / 2}\left[1-(1-X)^{1 / 2}\right]^{-1}$ & {$\left[1-(1-X)^{1 / 2}\right]^{2}$} \\
\hline & $\mathrm{N}_{\mathrm{n}}$ & Nucleation and nuclei growth & $\mathrm{n}(1-X)[-\ln (1-X)]^{(\mathrm{n}-1) / \mathrm{n}}$ & {$[-\ln (1-X)]^{1 / n}$} \\
\hline 9 & $\mathrm{~N}_{1}$ & $\mathrm{n}=1$ & $1-X$ & $-\ln (1-X)$ \\
\hline 10 & $\mathrm{~N}_{3 / 2}$ & $\mathrm{n}=3 / 2$ & $(3 / 2)(1-X)[-\ln (1-X)]^{1 / 3}$ & {$[-\ln (1-X)]^{2 / 3}$} \\
\hline 11 & $\mathrm{~N}_{2}$ & $\mathrm{n}=2$ & $2(1-X)[-\ln (1-X)]^{1 / 2}$ & {$[-\ln (1-X)]^{1 / 2}$} \\
\hline 12 & $\mathrm{~N}_{3}$ & $\mathrm{n}=3$ & $3(1-X)[-\ln (1-X)]^{2 / 3}$ & {$[-\ln (1-X)]^{1 / 3}$} \\
\hline \multirow[t]{2}{*}{13} & $\mathrm{~N}_{4}$ & $\mathrm{n}=4$ & $4(1-X)[-\ln (1-X)]^{3 / 4}$ & {$[-\ln (1-X)]^{1 / 4}$} \\
\hline & $S_{n}$ & Shrinking core & $\mathrm{n}(1-X)^{(\mathrm{n}-1) / \mathrm{n}}$ & $1-(1-X)^{1 / \mathrm{n}}$ \\
\hline 14 & $\mathrm{~S}_{1 / 2}$ & $\mathrm{n}=1 / 2$ & $(1 / 2)(1-X)^{-1}$ & $1-(1-X)^{2}$ \\
\hline 15 & $\mathrm{~S}_{1 / 3}$ & $\mathrm{n}=1 / 3$ & $(1 / 3)(1-X)^{-2}$ & $1-(1-X)^{3}$ \\
\hline 16 & $\mathrm{~S}_{1 / 4}$ & $\mathrm{n}=1 / 4$ & $(1 / 4)(1-X)^{-3}$ & $1-(1-X)^{4}$ \\
\hline 17 & $\mathrm{~S}_{2}$ & $\mathrm{n}=2$ & $2(1-X)^{1 / 2}$ & $1-(1-X)^{1 / 2}$ \\
\hline \multirow[t]{2}{*}{18} & $\mathrm{~S}_{3}$ & $\mathrm{n}=3$ & $3(1-X)^{2 / 3}$ & $1-(1-X)^{1 / 3}$ \\
\hline & $C_{n}$ & Chemical reaction & $(1-X)^{\mathrm{n}}$ & {$\left[1-(1-X)^{1-\mathrm{n}}\right] /(1-\mathrm{n})$} \\
\hline 19 & $\mathrm{C}_{3 / 2}$ & $\mathrm{n}=3 / 2$ & $2(1-X)^{3 / 2}$ & $(1-X)^{-1 / 2}$ \\
\hline 20 & $\mathrm{C}_{2}$ & $\mathrm{n}=2$ & $(1-X)^{2}$ & $(1-X)^{-1}-1$ \\
\hline 21 & $\mathrm{C}_{3}$ & $\mathrm{n}=3$ & $(1-X)^{3}$ & $(1 / 2)\left[(1-X)^{-2}-1\right]$ \\
\hline
\end{tabular}
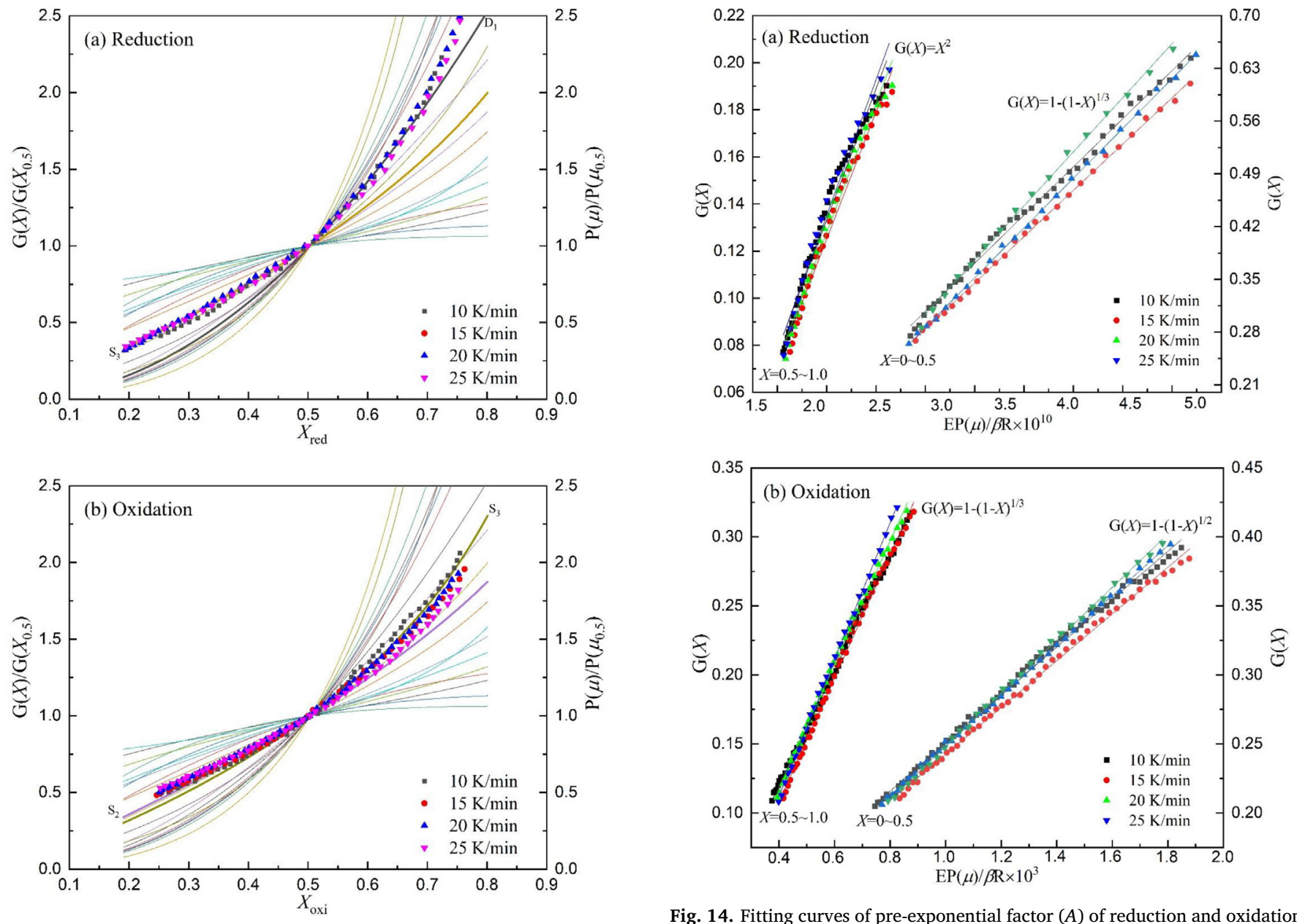

Fig. 13. Standard and experimental curves of reduction and oxidation.

Fig. 14. Fitting curves of pre-exponential factor $(A)$ of reduction and oxidation. 
Table 5

Values of $E, A$ and $f(X)$.

\begin{tabular}{|c|c|c|c|c|}
\hline \multirow[t]{2}{*}{ Step } & \multicolumn{2}{|l|}{ Reduction } & \multicolumn{2}{|l|}{ Oxidation } \\
\hline & $X<0.5$ & $X \geq 0.5$ & $X<0.5$ & $X \geq 0.5$ \\
\hline$E(\mathrm{~kJ} / \mathrm{mol})$ & $206.5 \pm 7.8$ & $227.2 \pm 8.2$ & $61.3 \pm 2.7$ & $72.9 \pm 4.3$ \\
\hline$A\left(\mathrm{~s}^{-1}\right)$ & $(4.21 \pm 0.28) \cdot 10^{8}$ & $(3.47 \pm 0.13) \cdot 10^{8}$ & $(1.79 \pm 0.12) \cdot 10^{2}$ & $(4.52 \pm 0.33) \cdot 10^{2}$ \\
\hline$f(X)$ & $3(1-X)^{2 / 3}$ & $(1 / 2) X^{-1}$ & $2(1-X)^{1 / 2}$ & $3(1-X)^{2 / 3}$ \\
\hline
\end{tabular}

for the reduction and oxidation reactions. The results show the activation energies differ very little for conversions in the range of $0.2-0.5$, and also for conversions in the range of $0.5-0.8$. The activation energies are lower at lower conversions compared to those at higher conversions, because at higher conversions the temperatures increase to a higher level.

Based on the results for the activation energies, it can be concluded that both the reduction and oxidation processes cannot be described accurately with a single mechanism function. The master curve method was applied to determine the most probable mechanism function of the redox reaction. Using the common gas-solid mechanism functions listed in Table 4, a series of standard curves of $\mathrm{G}(X) / \mathrm{G}\left(X_{0.5}\right)$ are obtained $[23,36,47-51]$. Based on the derived values of the activation energies, experimental curves of $P(u) / P\left(u_{0.5}\right)$ for the four different heating rates are obtained. The standard and experimental curves are shown in Fig. 13. For the most probable mechanism function, Eq. (22) can be set up:

$\frac{G(X)}{G\left(X_{0.5}\right)}=\frac{P(u)}{P\left(u_{0.5}\right)}$

For the reduction step, when the conversion of the oxygen carrier is lower than 0.5 , the four experimental curves and the standard curve of $\mathrm{S}_{3}$ have a good correspondence, and the shrinking core model with reaction order of 3 can describe this process adequately. When the conversion of the oxygen carrier reaches values above 0.5 , the four experimental curves and the standard curve of $\mathrm{D}_{1}$ correspond well, and the one-dimensional diffusion model can describe this process accurately. At the beginning of reduction, the oxygen is firstly released from the surface layer and then is released from the interior. The oxygen uncoupling of the oxygen carrier is exothermic and the heat was firstly used for the reaction and then to heat the particles, which is a shrinking core process. When the conversion is higher than 0.5 , the oxygen released from the inside must diffuse to the surface of the particle firstly, where the diffusion rate becomes rate limiting.

For the oxidation, when the conversion of oxygen carrier is lower than 0.5, the four experimental curves and the standard curve of $S_{2}$ show good correspondence, and the shrinking core model with reaction order of 2 can describe this process accurately. When the conversion of oxygen carrier becomes above 0.5 , the four experimental curves and the standard curve of $S_{3}$ agree well, and the shrinking core model with reaction order of 3 describes this process quite adequately. For the oxidation step, the active phase in the oxygen carrier particles needs to be into contact with air to oxidize, which entails that the oxygen from the air is firstly absorbed by the surface layer and then followed by a bulk absorption process to transfer the oxygen from the surface to the core of the particles.

Substitution of the calculated activation energies and the determined most probable mechanism function into Eq. (17), followed by linear fitting of $G(X)$ and $E P(\mu) / \beta \mathrm{R}$, the pre-exponential factors under the four different heating rates can be calculated from the slopes of the fitted curves. Fig. 14 shows the fitting curves of pre-exponential factor $(A)$ of the reduction and oxidation reactions of the oxygen carriers. It can be seen that the fitting curves have a good linear correlation under different heating rates. Moreover, both for the reduction and oxidation reactions, the fitting curves, and thus the pre-exponential factors, for the four different heating rates are very similar. Through the above analysis, the three kinetic factors of $E, A$ and $f(X)$ are all obtained and shown in Table 5. Summarizing, the kinetic models for the redox reaction are thus established:

For the reduction step:

$X<0.5: \frac{d X}{d t}=1.26 \cdot 10^{9} \exp \left(\frac{-2.48 \times 10^{4}}{T}\right)(1-X)^{2 / 3}$

$X \geqslant 0.5: \frac{d X}{d t}=1.74 \cdot 10^{8} \exp \left(\frac{-2.73 \times 10^{4}}{T}\right) X^{-1}$

For the oxidation step:

$X<0.5: \frac{d X}{d t}=3.58 \cdot 10^{2} \exp \left[\frac{-7.37 \times 10^{3}}{T}\right](1-X)^{1 / 2}$

$X \geqslant 0.5: \frac{d X}{d t}=1.36 \cdot 10^{3} \exp \left(\frac{-8.77 \times 10^{3}}{T}\right)(1-X)^{2 / 3}$

\section{Conclusions}

In this paper, a Cu-Mn/Zr composite oxygen carrier with a relatively low oxygen uncoupling temperature was prepared. The active phases in the oxidized and reduced state are $\mathrm{Cu}_{x} \mathrm{Mn}_{3-x} \mathrm{O}_{4}$ and $\mathrm{Cu}_{x} \mathrm{Mn}_{2-x} \mathrm{O}_{2}$, respectively. The prepared oxygen carrier shows a loose structure and the $\mathrm{Cu}, \mathrm{Mn}$ and $\mathrm{O}$ elements are distributed uniformly across the surface. The surface area is relatively small, and the crushing strength is high. The oxygen transport capacity is determined as $0.0463 \mathrm{~g} \mathrm{O}_{2} / \mathrm{g}$ oxygen carrier.

Compared to a Cu-based oxygen carrier, the oxygen uncoupling temperature is decreased and the values of equilibrium oxygen concentration at the same reaction temperature is increased greatly. The basic thermodynamic properties, viz. $\Delta G$ and $K_{\mathrm{p}}$ of the redox reaction, were obtained: $\Delta G=-0.119 T+150.41$ and $K_{p}=$ $\exp (14.31-18090.8 / T)$.

Both the reduction and oxidation reactions are temperature driven at the investigated temperatures. Based on the experimental data under the four heating rates, the reduction and oxidation kinetic models were established using the isoconversional method. The shrinking core model and diffusion model can adequately describe the redox reaction rates at different reduction and oxidation conversions, and the activation energies and pre-exponential factors were determined.

\section{Acknowledgement}

This research was financially supported by the National Natural Science Foundation of China (51604078, 51576035); Fundamental Research Funds for the Central Universities (N182504011, N172502006); China Scholarship Council (201906085017, 201806080086).

\section{References}

[1] J. Adánez, A. Abad, F. Garcia-Labiano, P. Gayan, L.F. de Diego, Progress in chemical-looping combustion and reforming technologies, Prog. Energy Combust Sci 38 (2) (2012) 215-282.

[2] A.H. Sahir, H.Y. Sohn, H. Leion, J.S. Lighty, Rate analysis of chemical-looping with oxygen uncoupling (clou) for solid fuels, Energy Fuel 26 (2012) 4395-4404. 
[3] K. Mayer, S. Piesenberger, S. Penthor, T. Pröll, H. Hofbauer, Chemical looping combustion using two different perovskite based oxygen carriers: a pilot study, Energy Technol. 6 (12) (2018) 2333-2343.

[4] M. Luo, Y. Yi, S.Z. Wang, Z.L. Wang, M. Du, J.F. Pan, Q. Wang, Review of hydrogen production using chemical-looping technology, Renew. Sustain. Energy Rev. 81 (2) (2018) 3186-3214.

[5] H.R. Ding, Y.Q. Xu, C. Luo, Q.Y. Wang, C. Shen, J.X. Xu, L.Q. Zhang, A novel composite perovskite-based material for chemical-looping steam methane reforming to hydrogen and syngas, Energy Convers. Manage. 171 (1) (2018) 12-19.

[6] T.L. Hsieh, Y.T. Zhang, D.K. Xu, C.H. Wang, M. Pickarts, C. Chung, L.S. Fan, A. Tong, Chemical looping gasification for producing high purity, $\mathrm{h}_{2}$-rich syngas in a cocurrent moving bed reducer with coal and methane cofeeds, Ind. Eng. Chem. Res. 57 (7) (2018) 2461-2475.

[7] J. Adánez, L.F. de Diego, F. García-Labiano, P. Gayán, A. Abad, J.M. Palacios, Selection of oxygen carriers for chemical-looping combustion, Energy Fuel 18 (2) (2004) 371-377.

[8] K. Wang, Q.B. Yu, Qin Qin, The thermodynamic method for selecting oxygen carriers used for chemical looping air separation, J. Therm. Anal. Calorim 112 (2) (2013) 747-753.

[9] P. Cho, T. Mattisson, A. Lyngfelt, Comparison of iron-, nickel-, copper-and manganese-based oxygen carriers for chemical-looping combustion, Fuel 83 (9) (2004) 1215-1225.

[10] M.M. Hossain, H.I.D. Lasa, Reduction and oxidation kinetics of Co- $\mathrm{Ni}_{1} / \mathrm{Al}_{2} \mathrm{O}_{3}$, oxygen carrier involved in a chemical-looping combustion cycles, Chem. Eng. Sci. 65 (1) (2010) 98-106.

[11] F. He, Y.G. Wei, H.B. Li, H. Wang, Synthesis gas generation by chemical-looping reforming using ce-based oxygen carriers modified with $\mathrm{fe}, \mathrm{cu}$, and mn oxides, Energy Fuel 23 (4) (2009) 2095-2102.

[12] S. Mukherjee, P. Kumar, A.D. Yang, P. Fennell, A systematic investigation of the performance of copper-, cobalt-, iron-, manganese- and nickel-based oxygen carriers for chemical looping combustion technology through simulation models, Chem. Eng. Sci. 130 (7) (2015) 79-91.

[13] P. Moldenhauer, M. Rydén, T. Mattisson, A. Lyngfelt, Chemical-looping combustion and chemical-looping with oxygen uncoupling of kerosene with $\mathrm{Mn}$ - and Cu-based oxygen carriers in a circulating fluidized-bed 300W laboratory reactor, Fuel Proc. Technol. 104 (2012) 378-389.

[14] Q. Imtiaz, M. Broda, C.R. Müller, Structure-property relationship of co-precipitated Cu-rich, $\mathrm{Al}_{2} \mathrm{O}_{3}$ - or $\mathrm{MgAl}_{2} \mathrm{O}_{4}$-stabilized oxygen carriers for chemical looping with oxygen uncoupling (CLOU), Appl. Energy 119 (2014) 557-565.

[15] K. Wang, Q.B. Yu, Long-lasting investigation of the Cu-based oxygen carrier particles in chemical looping air separation, Powder Technol. 343 (2019) 40-48.

[16] B. Moghtaderi, Application of chemical looping concept for air separation at high temperatures, Energy Fuel 24 (2010) 190-198.

[17] K. Shah, B. Moghtaderi, T. Wall, Effect of flue gas impurities on the performance of a chemical looping based air separation process for oxy-fuel combustion, Fuel 103 (2013) 932-942.

[18] K. Wang, Q.B. Yu, Z.L. Zuo, L.M. Hou, Q. Qin, Redox performance of Cu-based oxygen carrier used in chemical looping air separation combined oxy-fuel combustion technology, Appl. Therm. Eng. 98 (2016) 440-448.

[19] L.F. Diego, F. García-Labiano, J. Adánez, Development of Cu-based oxygen carriers for chemical-looping combustion, Fuel 83 (13) (2004) 1749-1757.

[20] X.M. Zheng, Q.Q. Su, W.L. Mi, study of a Cu-based oxygen carrier based on a chemical looping combustion process, Energy Fuel 29 (6) (2015) 3933-3943.

[21] P. Wang, B. Howard, N. Means, D. Shekhawat, D. Berry, Coal chemical-looping with oxygen uncoupling (CLOU) using a Cu-based oxygen carrier derived from natural minerals, Energies 12 (2019) 1-13.

[22] A. Cabello, P. Gayan, F. Garcia-Labiano, L.F. de Diego, A. Abad, J. Adánez, On the attrition evaluation of oxygen carriers in Chemical Looping Combustion, Fuel Process Technol. 148 (2016) 188-197.

[23] K. Wang, Q.B. Yu, Q. Qin, Z.L. Zuo, T.W. Wu, Evaluation of Cu-based oxygen carrier for chemical looping air separation in a fixed-bed reactor, Chem. Eng. J. 287 (2016) 292-301.

[24] I. Adánez-Rubio, M. Arjmand, H. Leion, P. Gayán, A. Abad, T. Mattisson, A. Lyngfelt, Investigation of combined supports for cu-based oxygen carriers for chemical-looping with oxygen uncoupling (CLOU), Energy Fuel 27 (2013) 3918-3927.

[25] A. Cabello, P. Gayán, A. Abad, L.F. de Diego, F. García-Labiano, M.T. Izquierdo, A. Scullard, G. Williams, J. Adánez, Long-lasting Cu-based oxygen carrier material for industrial scale in chemical looping combustion, Int. J. Greenh. Gas Con 52 (2016) 120-129.

[26] S.M. Liu, D.H. Lee, M. Liu, L.L. Li, R. Yan, Selection and application of binders for $\mathrm{CaSO}_{4}$ oxygen carrier in chemical-looping combustion, Energy Fuel 24 (12) (2010) 6675-6681.
[27] L.M. Hou, Q.B. Yu, K. Wang, F. Yang, T.Y. Wu, Oxidation and reduction kinetic of $\mathrm{YBaCo}_{4} \mathrm{O}_{7+\delta}$ and substituted oxygen carriers, J. Therm. Anal. Calorim. 134 (3) (2018) 2213-2221.

[28] J.H. Hwang, J.I. Baek, H.J. Ryu, J.M. Sohn, K.T. Lee, Development of $\mathrm{MgMnO}_{3}$ delta as an oxygen carrier material for chemical looping combustion, Fuel 231 (2018) 290-296.

[29] A. Shulman, E. Cleverstam, T. Mattisson, A. Lyngfelt, Manganese/Iron, Manganese/ Nickel, and Manganese/Silicon oxides used in chemical-looping with oxygen uncoupling (CLOU) for combustion of methane, Energy Fuel 23 (2009) 5269-5275.

[30] G. Azimi, H. Leion, T. Mattisson, M. Rydén, F. Snijkers, A. Lyngfelt, Mn - Fe Oxides with support of $\mathrm{MgAl}_{2} \mathrm{O}_{4}, \mathrm{CeO}_{2}, \mathrm{ZrO}_{2}$ and $\mathrm{Y}_{2} \mathrm{O}_{3}-\mathrm{ZrO}_{2}$ for chemical-looping combustion and chemical-looping with oxygen uncoupling, Ind. Eng. Chem. Res. 53 (2014) 10358-10365.

[31] N.M. Pour, H. Leion, M. Rydén, T. Mattisson, Combined Cu/Mn Oxides as an oxygen carrier in chemical looping with oxygen uncoupling (CLOU), Energy Fuel 27 (2013) 6031-6039.

[32] F.C.M. Driessens, G.D. Rieck, Phase equilibria in the system Cu-Mn-O, Z. Anorg. Allg. Chem. 35 (1967) 48-55.

[33] Z.Q. Wang, Y.Q. Liu, J.L. Wu, T. He, J.Q. Li, J.H. Wu, Preparation of large granular Cu-Based oxygen carriers by mechanical mixing for packed bed chemical-looping combustion, Energy Fuel 28 (2014) 7662-7671.

[34] Q. Zhao, C.J. Liu, L.H. Cao, M.F. Jiang, B.K. Li, H. Saxén, R. Zevenhoven, Shearforce based stainless steel slag modification for chromium immobilization, ISIJ Int. 59 (2019) 583-589.

[35] L.M. Neal, S. Yusuf, J.A. Sofranko, F.X. Li, Oxidative dehydrogenation of ethane: a chemical looping approach, Energy Technol 4 (2016) 1200-1208.

[36] K. Wang, Q.B. Yu, Q. Qin, Reduction kinetics of Cu-based oxygen carriers for chemical looping air separation, Energy Fuel 27 (9) (2013) 5466-5474.

[37] K. Shah, B. Moghtaderi, T. Wall, Selection of suitable oxygen carriers for chemical looping air separation: a thermodynamic approach, Energy Fuel 26 (4) (2012) 2038-2045.

[38] D. Hosseini, Q. Imtiaz, P.M. Abdala, $\mathrm{CuO}$ promoted $\mathrm{Mn}_{2} \mathrm{O}_{3}$-based materials for solid fuel combustion with inherent $\mathrm{CO}_{2}$ capture, J. Mater. Chem. A 3 (19) (2015) $10545-10550$.

[39] H. Wang, Z.S. Li, N.S. Cai, A multiscale model of oxidation kinetics for Cu-based oxygen carrier in chemical looping with oxygen uncoupling, Materials 12 (7) (2019) 1-18.

[40] J.A. Medrano, I. Potdara, J. Melendez, V. Spallina, D.A. Pacheco-Tanaka, M. van Sint Annaland, F. Gallucci, The membrane-assisted chemical looping reforming concept for efficient $\mathrm{H}_{2}$ production with inherent $\mathrm{CO}_{2}$ capture: Experimental demonstration and model validation, Appl. Energy 215 (2018) 75-86.

[41] C. Dueso, M. Ortiz, A. Abad, F. Garcia-Labiano, L.F. de Diego, P. Gayan, J. Adánez, Reduction and oxidation kinetics of nickel-based oxygen-carriers for chemicallooping combustion and chemical-looping reforming, Chem .Eng. J. 188 (2012) $142-154$.

[42] S.Y. Chuang, J.S. Dennis, A.N. Hayhurst, S.A. Scott, Kinetics of the chemical looping oxidation of $\mathrm{CO}$ by a co-precipitated mixture of $\mathrm{CuO}$ and $\mathrm{Al}_{2} \mathrm{O}_{3}$, Proc. Combust. Inst. 32 (2009) 2633-2640.

[43] A. Abad, J. Adánez, F. García-Labiano, L.F. de Diego, P. Gayán, Modeling of the chemical-looping combustion of methane using a Cu-based oxygen-carrier, Combust Flame 157 (2010) 602-615.

[44] J. Sestak, G. Berggren, Study of the kinetics of the mechanism of solid-state reactions at increased temperature, Thermochim. Acta 3 (1971) 1-12.

[45] S. Vyazovkina, A.K. Burnhamb, J.M. Criadoc, A.L. Pérez-Maquedac, C. Popescud, N. Sbirrazzuolie, ICTAC kinetics committee recommendations for performing kinetic computations on thermal analysis data, Thermochim. Acta 520 (2011) 1-19.

[46] K. Coenen, F. Gallucci, E. Hensen, M. van Sint Annaland, Kinetic model for adsorption and desorption of $\mathrm{H}_{2} \mathrm{O}$ and $\mathrm{CO}_{2}$ on hydrotalcite-based adsorbents, Chem. Eng. J. 355 (2019) 520-531.

[47] W.J. Duan, Q.B. Yu, H.Q. Xie, Q. Qin, Pyrolysis of coal by solid heat carrier-experimental study and kinetic modeling, Energy 135 (15) (2017) 317-326.

[48] Z.Y. Niu, G.J. Liu, H. Yin, D. Wu, C.C. Zhou, Investigation of mechanism and kinetics of non-isothermal low temperature pyrolysis of perhydrous bituminous coal by in-situ FTIR, Fuel 172 (15) (2016) 1-10.

[49] N.A. Rashidi, S. Yusup, B.H. Hameed, Kinetic studies on carbon dioxide capture using lignocellulosic based activated carbon, Energy 61 (2013) 440-446.

[50] T. Wang, J. Liu, H. Huang, M. Fang, Z. Luo, Preparation and kinetics of a heterogeneous sorbent for CO2 capture from the atmosphere, Chem. Eng. J. 284 (2016) 679-686.

[51] I. Adánez-Rubio, P. Gayán, A. Abad, F. García-Labiano, L.F. de Diego, J. Adánez, Kinetic analysis of a Cu-based oxygen carrier: Relevance of temperature and oxygen partial pressure on reduction and oxidation reactions rates in Chemical Looping with Oxygen Uncoupling (CLOU), Chem. Eng. J. 256 (2014) 69-84. 